\title{
An Optimized Preparation Method to Obtain High-quality RNA from the
}

\section{Buds of Sunflowers}

\author{
Hao.Feng ${ }^{1,2}$, XiBao $\mathrm{Ma}^{1}$, Jun. Yang ${ }^{1,2}$ \\ ${ }^{1}$ College of Life Sciences, China West Normal University, Nanchong, Sichuan, P.R. China 637009 \\ ${ }^{2}$ Key Laboratory of Southwest China Wildlife Resources Conservation, Ministry of Education, China \\ West Normal University, Nanchong, Sichuan,P.R. China
}

Keywords: Sunflower Buds; RNA Extraction; Polyphenol; Polysaccharide

\begin{abstract}
In an attempt to isolate high-quality, total RNA from flower buds of sunflowers (Helianthus annuus). We have already improved the SDS method. After adding liquid nitrogen, we have to grind the material down. After that we add protein -DNA precipitation, wash it with the addition of different kinds of alcohol, such as $75 \%$ alcohol and precipitation. Then we add DEPC water and guanidine hydrochloride blend, $\mathrm{LiCl}$ overnight precipitation,and then wash it off with $75 \%$ alcohol, finally make it dissolved in $15 \mu \mathrm{L}$ DEPC water which collocated in minus 80 environment for storage. The total RNA is precipitated with $1 / 10$ volume of NaAc and 2 volumes of absolute ethanol to prevent contamination by polysaccharides. These experimental results show that the total RNA extracted by this method is of high purity and integrity, and the electrophoretic bands are clear. D260/D230, D260/D280 and RNA (g/100mg) are 2.05, 2.11 and 9.52, respectively. Total RNA can amplify the target gene fragment by PT-PCR. This improved method can be used to extract the high-quality RNA from the sunflower buds of the space mutation, in order to study the molecular mechanism of the next step.
\end{abstract}

\section{Introduction}

Sunflowers (Helianthus annuus L.) Asteraceae (Compositae) Helianthus annual herb that originated in North America, Peru and northern Mexico[1,2], the world's third largest oil crops [3], which good quality oil , high oil content, linoleic acid content of up to $60 \%[4,5]$, is one of the main oil crops in northern China. In 2002, we will be more than the Sichuan branch of sunflowers space after mutagenic treatment were screened from the progeny of the experimental material, and its general management, bagged inflorescence mutant trait get multiple lines stably inherited.

RNA plays a very important role in the process of plant trait heredity, and the extraction of high-quality and integrity of RNA is the premise of cloning gene. Different plants, tissues or organs are in different growth and development periods of the rich in different materials [6];Even the same kind of plant in different cultivation conditions, rich in different materials, the corresponding, the RNA extraction methods are different. Previous experiments mostly use plant seeds and leaves as 
material, using conventional methods of Phenol-SDS, Trizol reagent method, guanidine thiocyanate phenol method is extracted. When we regard the sunflower buds as the material, according to the standard Phenol-SDS method, the RNA content is low, and the rRNA is not clear, which is not conducive to the development of the follow-up experiments. However, the purpose of this study is to use modified RNA extraction method, high-quality, integrity of RNA extraction from flower buds of sunflower.Being induced by space flight and for the study of sunflower mutation characters to the molecular mechanism of laid the foundation.

\section{Material And Methods}

In SP7 generation, we choose young flower buds and cotyledons as material, being cooled with liquid nitrogen immediately after picking,in $-80{ }^{\circ} \mathrm{C}$ preservation. Tobacco materials from greenhouse cultivation.

Preparation of solution and reagents. 1)Cell lysis: 2\% (w/v) SDS, $68 \mathrm{mM}$ sodium citrate, $132 \mathrm{mM}$ citric acid, 1 EDTA mM,0.5 g/L of Inferior amine.

2)Protein -DNA solution: $4 \mathrm{NaCl} \mathrm{M}, 16 \mathrm{mM}$ sodium citrate, $32 \mathrm{mM}$ citric acid

3) $8 \mathrm{~mol} / 1 \mathrm{LiCl}$

4) $10 \%(\mathrm{w} / \mathrm{v})$ Hydrochloric acid

5) DNase I (RNase Free, TaKaRa)

6) $75 \%$ ethanol ,Liquid nitrogen and DEPC-water

7) TAE buffer solution $(50+): 121 \mathrm{~g}$ Tris, $28.55 \mathrm{ml}$ glacial acetic acid, $9.306 \mathrm{~g}$ EDTA . $450 \mathrm{ml}$ dissolved with ultrapure water, with glacial acetic acid to adjust $\mathrm{pH}=8.0$ and later transferred to the volumetric flask, add ultra pure water till $500 \mathrm{ml}$, shake and after high temperature sterilization, and preservation. $1+$ buffer solution.

RNA extraction method of sunflower buds.In the extraction of total RNA, we use existing standard Phenol-SDS method [7], heath method [8], TakaRa rnaiso plus, rnaiso plus +RNAiso-mate for plant tissue, Canada Trizol kit were extracted.

Optimization method.1) Take $25 \mathrm{mg}$ material is thoroughly ground in liquid nitrogen environment, rapidly transferred to a $1.5 \mathrm{ml}$ microcentrifuge tube containing $300 \mu 1$ of cell lysate, the strong shock for 10 seconds at room temperature for $5 \mathrm{~min}$.

2) Add $100 \mu \mathrm{L}$ Protein -DNA precipitation solution, and then put upside down to reverse the full mixing, place it at $4^{\circ} \mathrm{C}$ for $6 \mathrm{~min}$, spin for $6 \mathrm{~min}$.

3) $300 \mu 1$ supernatant is transferred to new $1.5 \mathrm{ml}$ Eppendorf tube, plus $300 \mu 1$ isopropanol, mix it upside down, static at room temperature for $8 \mathrm{~min}$ and spin for $6 \mathrm{~min}$.

4) Discard the supernatant, $900 \mu 1$ volume concentration of $75 \%$ ethanol washed precipitation, dry it at room temperature for $2 \mathrm{~min}$, then add $40 \mu \mathrm{LEPC}$ water dilution of DNase solution, bath with water for $10 \mathrm{~min}$ at $37^{\circ} \mathrm{C}$.

5) Add $392 \mu \mathrm{L}$ DEPC water, guanidine hydrochloride $48 \mu \mathrm{L}$, mix it upside down, and spin for $3 \min$. 
6) The $480 \mu \mathrm{l}$ supernatant has been transferred to the new centrifugal tube, then add $160 \mu \mathrm{L}$ $\mathrm{LiCl}$ solution,mix it upside down under the condition of $-20^{\circ} \mathrm{C}$ for $30 \mathrm{~min}$,or overnight precipitation at $4{ }^{\circ} \mathrm{C}$.

7) Spin for $15 \mathrm{~min}$, and then wash with $900 \mu 175 \%$ ethanol, dry at room temperature for $3 \mathrm{~min}$, let it dissolved in $15 \mu 1 \mathrm{DEPC}$ water and save it at $-80^{\circ} \mathrm{C}$.

Special tip: the speed of the centrifuge is $14000 \mathrm{r} / \mathrm{min}$ at $4^{\circ} \mathrm{C}$.

Total RNA quality inspection. Determination of RNA OD :Take $2 \mu$ stoste, and determine the total RNA purity and concentration by NanoDrop2000/2000C, and the yield (yield) is calculated using the formula.

RNA output $(\mathrm{g} / 100 \mathrm{mg})=100 \mathrm{mg} \times$ RNA sample concentration $\times 15 \mu \mathrm{l} /$ grinding material quality.

Electrophoresis detection. Agarose gel electrophoresis is performed by using $5 \mu 1$ total RNA. Conditions of electrophoresis: agarose concentration $1 \%$, electrophoretic voltage and time respectively is $120 \mathrm{~V}$ and $20 \mathrm{~min}$ and stained with GreenView, then the gel imaging system is used to observe, photograph and record.

Primer design. Retrieved from the NCBI database to sunflower (Helianthus annuus) mRNA sequence catalase, actin and cyclin are long 1735b, 1134b and 1247b, GenBank accession number L28740, AF282624 and AF321361, we should use Primer Premier6.0 software for primer design, primer sequence:

Catalase upstream primer F: 5'-GATCCTTACAAGTACCGTTC-3 '

Catalase downstream primer R: 5'-ACCGATTACATAAACCCATC-3 '

Actin upstream primer F: 5'- GTGACAATGGAACAGGAATG -3 '

Actin downstream primer R: 5'- CACTTCCGGTGGACAATG -3 '

Cyclin upstream primer F: 5'-GAGTGAGAGGCTTTGTTCTC-3 '

Cyclin downstream primer R: 5'-AGCACAAATCCGTACCACG-3 '

RT-PCR.To space mutation sunflower mutant form flower buds of total RNA as a template, plus catalase and reverse primers, just according to PrimeScript. One Step RT-PCR Kit Ver.2 Operation Manual for reverse transcription and gene amplification. Reverse transcription reaction system $50 \mu$, including as follows:

\begin{tabular}{|c|c|c|c|c|}
\hline PrimeScript 1 Step Enzyme Mix & $2 \mu 1$ & $50^{\circ} \mathrm{C}$ & $30 \mathrm{~min}$ & 1cycle \\
\hline $2 \times 1$ Step Buffer & $25 \mu 1$ & $94^{\circ} \mathrm{C}$ & $2 \mathrm{~min}$ & 1cycle \\
\hline Upstream Primer & $1 \mu 1$ & $94^{\circ} \mathrm{C}$ & $30 \mathrm{sec}$ & \\
\hline Downstream Primer & $1 \mu 1$ & $46^{\circ} \mathrm{C}$ & $30 \mathrm{sec}$ & - 32cycles \\
\hline Template RNA & $3 \mu 1$ & $72^{\circ} \mathrm{C}$ & $102 \mathrm{sec}$ & \\
\hline RNase Free $\mathrm{dH}_{2} \mathrm{O}$ & $18 \mu 1$ & $72^{\circ} \mathrm{C}$ & $5 \mathrm{~min}$ & 1cycle \\
\hline Total volume & $50 \mu 1$ & $4^{\circ} \mathrm{C}$ & & Save \\
\hline
\end{tabular}

Description: catalase, actin and cyclin denaturation temperatures are $46{ }^{\circ} \mathrm{C}, 47{ }^{\circ} \mathrm{C}$ and $51{ }^{\circ} \mathrm{C}$; extension of time for the $102 \mathrm{~s}, 66 \mathrm{~s}$ and $75 \mathrm{~s}$; number of cycles is 32,30 and 35 respectively. 


\section{Results and analysis}

OD value results and analysis. Table 1-1 shows: RNA absorbance standard Phenol-SDS method to give a ratio of OD260 / OD230 and OD260 / OD280 were 0.85 and 1.53, less than 1.80, indicating that the total RNA sample obtained by this method in polyphenols, polysaccharides, proteins, phenol, salt ions and other serious pollutants, and pollution will also affect the absorbance of the polysaccharide, leading to calculate the total amount is incorrect. This may be due to plant flower buds contain a large number of polysaccharides, polyphenolic compounds and secondary metabolites and other substances. The polysaccharide easy to combine and form a co-precipitate RNA, difficult to purification[9]; polyphenols can easily be oxidized to quinones, irreversible binding to RNA $[10,11]$.

By optimization of RNA extracted from flower buds absorbance ratio OD260 / OD230 and OD260 / OD280 was 2.05 and 2.11, respectively, indicating that the RNA sample extraction method optimization of polyphenol, polysaccharide removing more thorough, less contaminated, no small molecules, ion interference, and total RNA $(9.52 \mu \mathrm{g} / 100 \mathrm{mg})$ obtained in yield than standard Phenol-SDS method $(8.29 \mu \mathrm{g} / 100 \mathrm{mg})$ higher; with the optimized method of separating material leaves and tobacco stalks of total RNA, which OD260 / OD230 and OD260 / OD280 were 1.98,2.11 and 2.34,2.18, significantly higher than the absorbance ratio Phenol-SDS purification of RNA from flower buds, and were about 2.00, indicating that the method is more suitable for total RNA was extracted from the experimental material; absorbance ratio RNA optimization method and the standard Phenol-SDS were isolated from tobacco leaves or less, were about 2.0, indicating that they are suitable for isolation of total RNA from the material.

\section{Electrophoresis test results and analysis}

RNA electrophoresis. Figure 1 shows: Optimization by chapter from space mutation sunflower flower buds isolated RNA bands were clear, without any smearing, no genomic DNA contamination and rRNA $28 \mathrm{~S} / 18 \mathrm{~S}$ strip brightness ratio was significantly greater than 2 , indicating that the method is extracted from the flower buds the protein-RNA, polysaccharides and polyphenolic compounds pollution, no small molecules and ionic contamination, is not degraded, good integrity; standard Phenol-SDS purification of RNA from flower buds fuzzy bands, there are serious tailing phenomenon, genomic DNA more pollution, rRNA 28S / 18S bands approximate brightness ratio, indicating the standard RNA extraction are degradation phenomena, small molecules, ions, proteins, polysaccharides and polyphenols pollution; Space Mutation sunflower leaf extract used herein and optimization tobacco stems, RNA leaves, clear bands, without any smearing, rRNA 28S / 18S strip brightness ratio were significantly greater than 2, no genomic DNA contamination and RNA isolated from tobacco leaves also look to distinguish 16SrRNA and tRNA Article band, indicating that the optimization method using RNA isolated from these three materials without proteins, polysaccharides, polyphenols pollution, no small-molecule, ion interference, RNA integrity, and no significant degradation phenomena; using standard methods from the above three materials total RNA was purified from a slight smearing, genomic pollution (lanes 4,5), rRNA of the $28 \mathrm{~S} / 18 \mathrm{~S}$ bands luminance is less than 2, indicating that the standard method of total RNA extracted from three materials, a slight contamination and RNA there are significant degradation 
phenomena.

Figure 2 shows: Phenol-SDS standard with RNA extracted from the material as a template and two kinds of actin and catalase gene was PCR amplified sunflower by electrophoresis bands were found, indicating that amplification failure; use optimization methods from the material isolated RNA as a template, and sunflower actin, catalase and cyclin three genes were amplified by agarose gel electrophoresis obvious bright band appears, and the actual size (actin is 1093bp, catalase is 1693bp, cyclin is $1216 \mathrm{bp}$ ) It coincides with the pre-amplified fragment, indicating the total RNA extracted by this method can effectively amplified gene fragment.

Combined OD value, total RNA agarose gel electrophoresis and RT-PCR electrophoresis figure shows: The optimization method can effectively extract from the material of high purity, non-polluting, good integrity of total RNA, by RT-PCR test, suitable for a downstream molecule experiments; and Phenol-SDS method using standard material from RNA isolated, OD ratio and gel electrophoresis is not ideal, and the pollution is more serious, by RT-PCR test does not yield the desired gene fragment is not suitable for follow-up experiment . In addition, the pharmaceutical formulation optimization method is simple, small economies and toxic, and easy to operate.

The catalase sequencing results with the original sequence and the NCBI alignment, homology was found $87.16 \%$, indicating that this method is suitable for optimization of total RNA isolated from Space Mutation sunflower flower buds suitable for downstream applications.

Discussion

Materials for the study of mutation leading to genetic and molecular mechanisms, our primary task is to extract high purity, good integrity test to continue downstream of total RNA. Whenwe use Phenol-SDS method[7], a result is bad, it is not conducive to the downstream trials. By Heath method [8], although simple, safe, but the pollution is serious, serious impact on downstream testing.

Sunflower young flower buds with a large number of polysaccharides, polyphenolic compounds and secondary metabolites and other substances. Currently, the method of isolating RNA from such plant material are: soluble PVP- ethanol precipitation, modified guanidine thiocyanate - phenol - chloroform method [12], improved hot borate method [13], a high molecular polyethylene glycol method, LiCl-2- butoxyethanol - LiCl method, potassium acetate, ethanol insoluble PVP- treatment method, LiCl precipitation method [14], silicon dioxide (silica) - method [15], isothiocyanate - vinegar acid method [16,17], CTAB method [18], Urea-LiCl-PVP method [19] and Urea- ethanol / isopropanol - acetate precipitation method [20] and so on. However, these methods are by phenol - removal of proteins, polysaccharides, polyphenols and secondary metabolites chloroform extraction, and some further added $\beta$-ME strong irritant drugs [16,18,20,21], precipitation RNA vinegar salt further remove contaminating polysaccharides[16,21], complicated operation, time-consuming, toxicity, there are some drawbacks.

The reports view, modify buffer may improve the extraction of leaves and buds in RNA content and purity to some extent [22,23]. In this author Li Z[10] and Heath et al. [11] reported improved method for space mutation sunflower flower bud RNA extraction. The key point of this method is that plant cells are lysed in cell lysates, while adding cysteine also prevents the plant material is 
oxidized polyphenols, mixed with added $\mathrm{NaCl}$, centrifugation can be fully removed mostly after cleavage proteins, polysaccharides, polyphenols and cell debris and other impurities, transfer the supernatant with an equal volume of isopropanol to give the crude product precipitated RNA. After DNase I treatment, re-dissolved guanidine hydrochloride, to give the final purified RNA by $\mathrm{LiCl}$ precipitation. SPACE FLIGHT purified by the method of total RNA sunflower flower buds, by absorption spectroscopy showed no polysaccharide, polyphenol, small molecules and ionic contamination; agarose gel electrophoresis analysis showed that the integrity of the RNA good; by RT-PCR test, to give the desired gene (actin, catalase, cyclin genes), show that the method can extract high quality RNA from aerospace induced sunflower flower buds. During the experiment, and non-irritating drugs ( $\beta$-ME) and an organic solvent (phenol, chloroform), and the solution configuration and operation of our non-toxic, safe, simple, low cost, RNA obtained genomic DNA contamination-free, high-purity, content, in order to further analyze the molecular mechanisms leading to the mutant trait is the foundation.

\section{Acknowledgments}

The research is supported by the Sichuan Provincial Youth Science and Technology Foundation (\#05ZQ026-017), and Sichuan Provincial Key Subject Programme (\#SZD0420), P. R. China.

National Natural Science Fund Project "long petals sunflower mutant lines related gene cloning and functional studies", number [31171587]

\section{References}

[1]Xiang LJ,Lei ZH,Shi BX,et al.(2010). Sunflower Oil Genetic Variation and Correlation Analysis of Quantitative Traits and Breeding Selection. Heilongjiang Agricultural Sciences. 9: 35-38.

[2]Zhong HQ,Wu JS,Chen SL,et al.(2009) Ornamental Sunflower RAPD Analysis of Genetic Diversity. Molecular Plant Breeding. 7 (1): 73-78.

[3]Zhang M(2010). Sunflower Breeding of Domestic and Commercial Activities.Heilongjiang Agricultural Science.6: 149-151.

[4]Hou XM,Wang DX,Sun EY(2010). Liaoning Fuel Sunflower Yield Cultivation Techniques.Cereal Plant.30 (2): 132-133.

[5]Jing L,Sha RN(2007). Progress Sunflower Tissue Culture.Northwest Botany.27 (1): 0201-0205.

[6]Ren ZK(2008). An Efficient Method of Total RNA Extraction from Peanut Seeds. Peanut Science 37:20-23.

[7]Li Z, Trick HN(2005). Rapid Method for High-quality RNA Isolation from Seed Endosperm Containing High Levels of Starch. BioTechniques.38(6):872-876.

[8]Heath EM, Minnetonka, Minn(1999). Low pH RNA Isolation Reagents, Method, and Kit. In. United States: Gentra Systems, Inc., Minneapolis, Minn.

[9]Gambino G, Perrone I, Gribaudo I(2008). A Rapid and Effective Method for RNA Extraction from Different Tissues of Grapevine and Other Woody Plants. Phytochemical Analysis.19(6):520-525.

[10]Ghangal R, Raghuvanshi S, Chand Sharma P (2009). Isolation of Good Quality RNA from a Medicinal Plant Seabuckthorn, Rich in Secondary Metabolites. Plant Physiology and Biochemistry 47(11-12):1113-1115. 
[11]Loomis WD(1974). Overcoming Problems of Phenolics and Quinones in the Isolation of Plant Enzymes and Organelles. Methods in Enzymology.31: 528-544.

[12]Siebert PD, Chenchik A(1993). Modified Acid Guanidinium Thiocyanate-phenol-chloroform RNA Extraction Method Which Greatly Reduces DNA Contamination. Nucleic Acids Research. 21(8):2019-2020.

[13]Wan CY, Wilkins TA(1994). A Modified Hot Borate Method Significantly Enhances the Yield of High-Quality RNA from Cotton (Gossypium hirsutum L.). Analytical Biochemistry. 223(1):7-12.

[14]Witchel HJ, Maitland NJ, Meech RW(1996). Milligram Quantity Preparation of RNA from a Marine Invertebrate with a High Fluid Content. Biotechniques.21(6):1024-1026.

[15]Ding LW, Sun QY, Wang ZY, et al.(2008). Using Silica Particles to Isolate Total RNA from Plant Tissues Recalcitrant to Extraction in Guanidine Thiocyanate. Analytical Biochemistry.374(2):426-428.

[16]Thanh T, Omar H, Abdullah M, et al.(2009) Rapid and Effective Method of RNA Isolation from Green Microalga Ankistrodesmus Convolutus. Molecular Biotechnology.43(2):148-153.

[17]Xu Q, Wen X, Tao N, et al.(2006). Extraction of High Quality of RNA and Construction of a Suppression Subtractive Hybridization (SSH) Library from Chestnut Rose (Rosa roxburghii Tratt). Biotechnology Letters.28(8):587-591.

[18]Wang L, Stegemann JP(2009). Extraction of High Quality RNA from Polysaccharide Matrices Using Cetlytrimethylammonium Uromide. Biomaterials.31(7):1612-1618.

[19]Tai H, Pelletier C, Beardmore T(2004). Total RNA Isolation from Picea Mariana Dry Seeds. Plant Molecular Biology Reporter.22(1):93-93.

[20]Almarza J, Morales S, Rincon L, et al.(2006). Urea as the Only Inactivator of RNase for Extraction of Total RNA from Plant and Animal Tissues. Analytical Biochemistry.358(1):143-145.

[21]Qi G, Li JT, Ruan QP, et al.(2009). An Optimised, Small-scale Preparation of High-quality RNA from Dry Seeds of Davidia Involucrata. Phytochemical Analysis.20(2):139-142.

[22]MacKenzie DJ, McLeanMA., Mukerji S, et al.(1997). Improved RNA Extraction from Woody Plants for the Detection of Viral Pathogens by Reverse Transcription-polymerase Chain Reaction. Plant Dis. 81, 222-226.

[23]Nassuth,A,Pollari E, Helmeczy,K,et al.(2000). Improved RNA Extraction and One-tube RT-PCR Assay for Simultaneous Detection of Control Plant RNA Plus Several Viruses in Plant Extracts. Virol. Methods.90:37-49.

Table 1-1 Optimization methods and standards Phenol-SDS method absorbance ratio comparison

\begin{tabular}{c|cccccc}
\hline \multirow{2}{*}{\begin{tabular}{c} 
Species \\
\cline { 2 - 7 }
\end{tabular}} & \multicolumn{2}{|c}{$A_{260} / A_{230}$} & \multicolumn{2}{c}{$A_{260} / A_{280}$} & \multicolumn{2}{c}{ RNA Yield ( $\boldsymbol{\mu g} / \mathbf{1 0 0 m g})$} \\
\cline { 2 - 7 } & Phenol-SDS & $\begin{array}{c}\text { Modified } \\
\text { Protocol }\end{array}$ & Phenol-SDS & $\begin{array}{c}\text { Modified } \\
\text { Protocol }\end{array}$ & Phenol-SDS & $\begin{array}{c}\text { Modified } \\
\text { Protocol }\end{array}$ \\
\hline Sunflower buds & $0.85 \pm 0.15$ & $2.05 \pm 0.15$ & $1.53 \pm 0.09$ & $2.11 \pm 0.03$ & $8.29 \pm 2.93$ & $9.52 \pm 4.27$ \\
Sunflower leaves & $1.38 \pm 0.06$ & $1.98 \pm 0.22$ & $1.79 \pm 0.04$ & $2.11 \pm 0.35$ & $3.77 \pm 1.18$ & $8.24 \pm 1.92$ \\
Tobacco leaves & $2.02 \pm 0.09$ & $2.30 \pm 0.06$ & $2.02 \pm 0.06$ & $2.18 \pm 0.03$ & $15.80 \pm 7.39$ & $12.80 \pm 6.28$ \\
Tobacco stalk & $1.48 \pm 0.18$ & $2.34 \pm 0.11$ & $1.55 \pm 0.03$ & $2.18 \pm 0.04$ & $1.65 \pm 0.60$ & $0.51 \pm 0.12$ \\
\hline
\end{tabular}




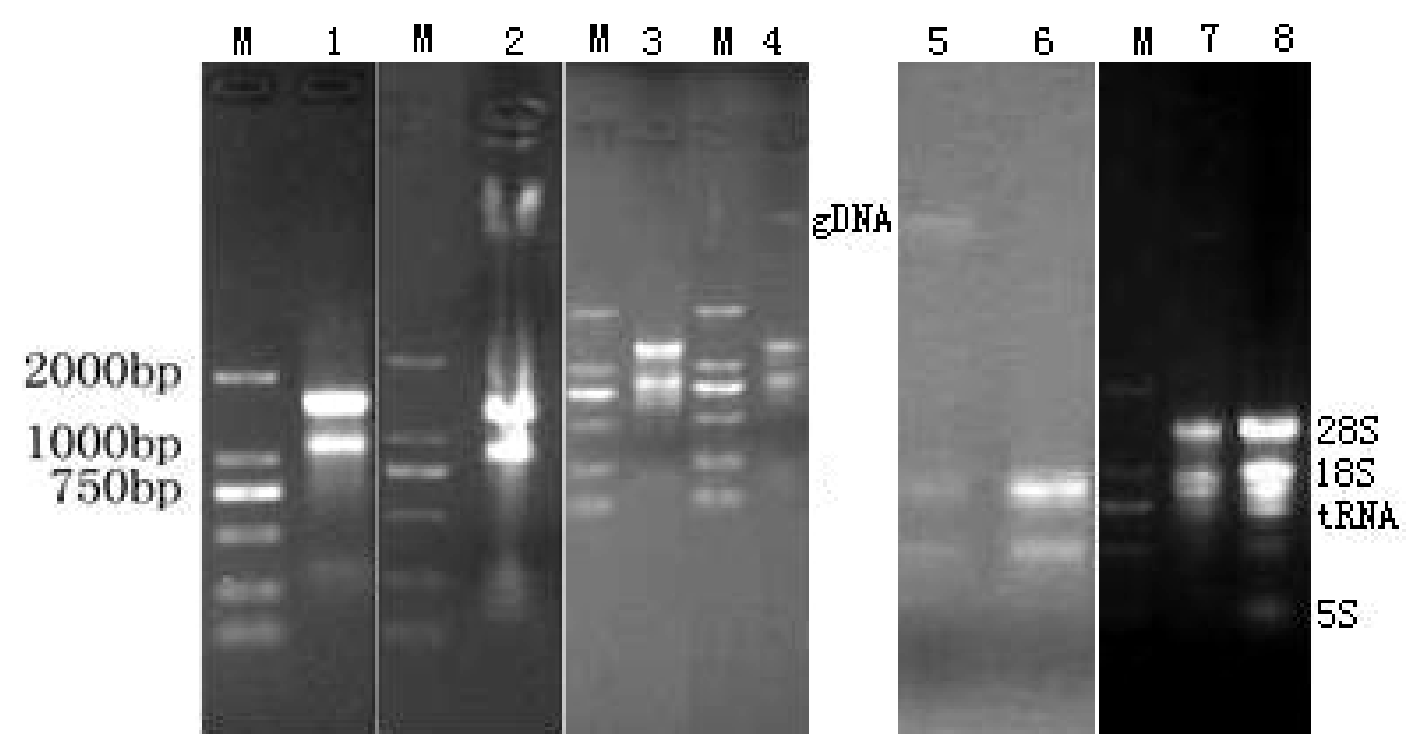

Figure 1. Sunflower buds space mutation analysis of total RNA electrophoresis

M: DL2000 (TaKaRa); lanes 1,3,6 and 8 are optimized purification sunflower buds, leaves, stems, and tobacco leaves, tobacco total RNA; lanes 4, 5 and 7 are standard Phenol-SDS method to extract sunflower buds, leaves, stems, and tobacco leaves, tobacco total RNA.

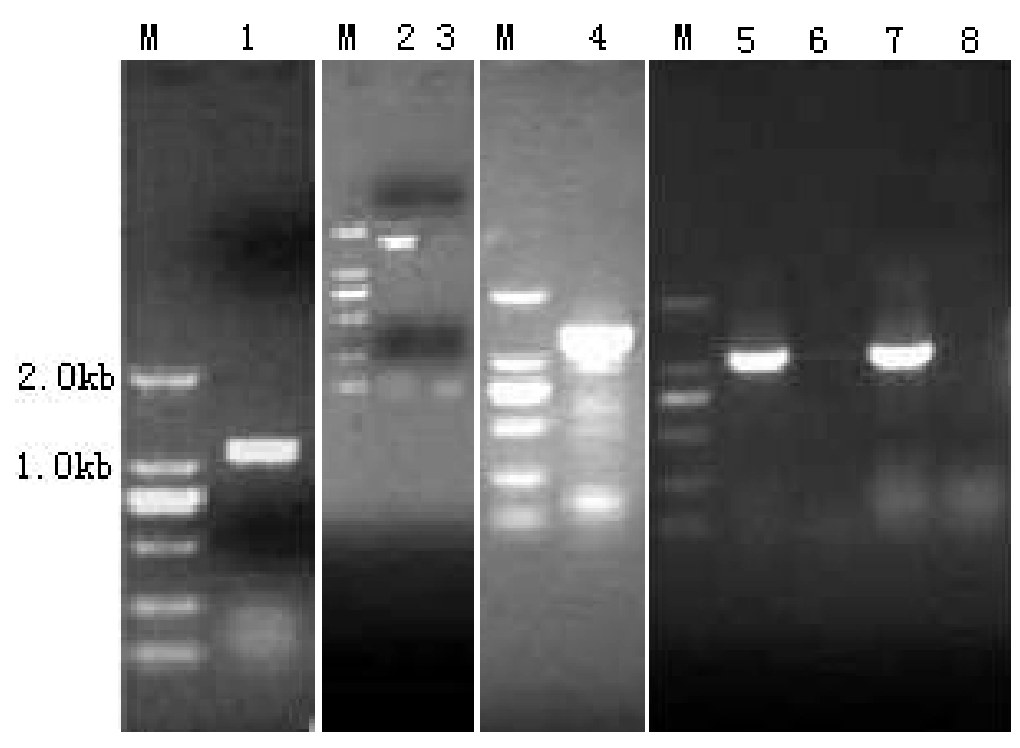

Figure 2. Space Mutation sunflower buds and leaves total RNA RT-PCR amplification of gene fragments results M: DL2000 (TaKaRa); 1 and 7,2,4 sunflower buds are extracted that RNA is amplified by optimizing actin, catalase, cyclin gene; 3, 6 and 8 are standard Phenol-SDS purification flower buds and leaves RNA amplification and catalase actin gene; 5 for the optimization leaf extract RNA amplification actin gene. 